\title{
National Adverse Drug Reaction Reporting System at the Ministry of Health, Saudi Arabia
}

\author{
Yousef Ahmed Alomi, (iD The \\ Former General Manager of General \\ Administration of Pharmaceutical \\ Care, The Former Head, National Clini- \\ cal pharmacy and pharmacy practice, \\ The Former Head, Pharmacy R and \\ D Administration, Ministry of Health, \\ Riyadh, SAUDI ARABIA. \\ Saeed Jamaan Alghamdi, General \\ Administration of Pharmaceutical \\ Care, Ministry of Health, Riyadh, \\ SAUDI ARABIA.
}

Radi Abdullah Alattyh, General Administration of Pharmaceutical Care, Ministry of Health, Riyadh, SAUDI ARABIA.

\section{Correspondence:}

Dr. Yousef Ahmed Alomi,

The Past General Manager of General Administration of Pharmaceutical Care, The Past Head, National Clinical Pharmacy and Pharmacy Practice, The Past Head, Pharmacy R and D Administration, Ministry of Health, Riyadh, SAUDI ARABIA.

Phone no: +966504417712

E-mail: yalomi@gmail.com

Received: 25-07-2018;

Accepted: 10-09-2018

Copyright: $\odot$ the author(s),publisher and licensee Pharmacology, Toxicology and Biomedical Reports. This is an open-access article distributed under the terms of the Creative Commons Attribution NonCommercial License, which permits unrestricted non-commercial use, distribution, and reproduction in any medium, provided the original work is properly cited.

This is an open access article distributed under the terms of the Creative Commons Attribution-NonCommercial-ShareAlike 4.0 License

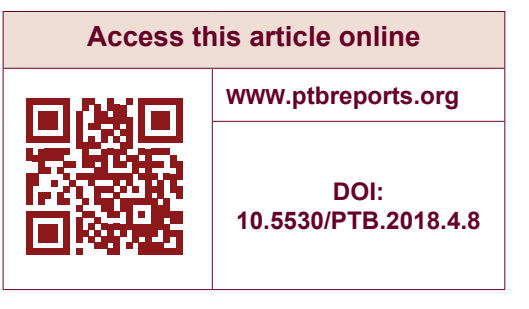

\begin{abstract}
Objective: To illustrate the adverse drug reaction during the pharmacy strategic plan at the Ministry of Health of Health institutions in the Kingdom of Saudi Arabia. Method: It is description analysis of adverse drug reaction system at the Ministry of Health of Health institutions. It was analysis within the Pharmacy strategic plan 2012-2020. The modified pharmacy business model system and Project Management Procedure used in the report. Results: The adverse drug reaction established with a defined vision, mission and goals. The system human or economic and other resources described in the review. The risk management was discussed to assure the continuation of the system. Besides, the monitoring and controlling of the system as illustrated. The closing stage with convention to operation project demonstrated in the Analysis. Conclusion: The Adverse drug reaction system implemented and it is considered as part of the healthcare system and pharmacy regulations. The documentation of ADR is updating improving accordingly at all Ministry of Health institutions in the Kingdom of Saudi Arabia.
\end{abstract}

Key word: Adverse Drug Reaction, System, Pharmaceutical Care, Ministry of Health, Saudi Arabia.

\section{INTRODUCTION}

The documentation and reporting system of Adverse Drug Reaction (ADR)is one of the requirements mandated for international and national accreditation of healthcare institutions. ${ }^{1,2}$ In addition, it is a part of the requirement from the registration agency in the Kingdom of Saudi Arabia (KSA). Regulations about the ADR reporting system have been released from various pharmaceutical societies and local and international registration agencies. ${ }^{3}$ Till date, several investigations have focused on different perspectives of ADR such as ADR reporting system, knowledge on the ADR reporting system and perception of pharmacists/healthcare provider regarding the ADR reporting system. ${ }^{4,5}$ However, to the best of our knowledge, there are no studies with regard to the description of the program in the Ministry of Health $(\mathrm{MOH})$ and how it was established, the requirement of resources and the analysis of marketing with Strength, Weakness, Opportunity and Threats (SWOT). Therefore, in this review, we aim to explore the national ADR system at the $\mathrm{MOH}$ by using the Project Management tools in the KSA.

\section{Method of Development of the Project}

The task force committee consisted of expert people from the pharmacies of the $\mathrm{MOH}$ hospitals to set up a national ADR system for the pharmacies of hospitals, PHCs and dental centers. The first author of this article headed the medication safety committee; he conducted regular periodical meetings. The committee unitized and drove the pharmacy ADR of the General Administration of Pharmaceutical Care (GAPC) and from non$\mathrm{MOH}$ hospitals system. Moreover, by the project written by using the international business model, pharmacy guidelines, project management institution guidelines for a new project. ${ }^{6-9}$ The draft was sent to several reviewers of the RAPC. The selection was corrected and updated accordingly. Then, the second draft was submitted to the reviewers for their final comments and approval. This took around 4 months to complete the task. The GAPC at the MOH sent the final document to all the hospitals for implementation. The ADR documentation system consists of the following parts: initial phase, planning phase, execution phase, monitoring and controlling aspect.

\section{Initial Phase \\ Assessment Needs}

At any given time, pharmacy departments of any healthcare institution will have hundreds of medications stored for dispensing. All medications had ADRs documented through drug reference. In addition to causing an economic burden on the healthcare system, an ADR might cause serious problems to the patients which may even be fatal. The best method to prevent ADR is to report them whenever they occur. The prevention of $\mathrm{ADR}$ need the documentation of $\mathrm{ADR}$ and related information in the future.

\section{Market Analysis}

ADR documentation system was established in the early 2000s at the MOH's administration of 
the pharmaceutical care unit. The first draft was updated during 2012$2015 .{ }^{10}$ Several non-MOH institutions have their own system of ADR documentation, which could be either electronically or manually documented. Most private hospitals have manual ADR. Earlier there was a manual documentation system of ADR at the MOH institutions, which was then converted to an electronic form through the SurveyMonkey system.

\section{SWOT Analysis}

To meet the project goals, we performed a SWOT analysis. The "strengths" of the project were accompanied by the documentation of pharmacy workload for the prevention of medication errors, the calculated cost of avoidance of medication errors and the calculated cost of correction of medication errors. The "weaknesses" in this project were accompanied by increased pharmacy workload and misuse of documentation through the evaluation of the performance of pharmacy staff. The "opportunities" examined in this review included the implementation of national and international standards of healthcare institutions, implementation of New Saudi Vision 2030 and the calculated cost of medication errors. ${ }^{11}$ Among the "threats," changes in the pharmacy administration and the accreditation standards were analyzed.

\section{Planning Phase}

The Scope of the Project

The ADR documentation collects demographic data of the patient, severity and causality of the ADR, the person identifying the ADR, reasons of ADR, the medications involved, the analysis of ADR and the reporting of ADR to the Saudi Food and Drug Authority (SFDA).

\section{Vision, Missions and Goals}

The vision of this project is to define the best system of ADR documentation and related information and prevention of medication errors at the $\mathrm{MOH}$ institutions. The mission is to provide the ADR documentation and prevention system at $\mathrm{MOH}$ institutions so that there is a reduction in morbidity, mortality and economic burden on the healthcare system due to ADR in the KSA. Goals of this project were to facilitate ADR documentation at $\mathrm{MOH}$ institutions, analyze the $\mathrm{ADR}$, prevent $\mathrm{ADR}$ complications and document the cost avoidance related to the prevention of ADR.

\section{Description of the Project}

The identified ADRs are based on the SFDA, World Health Organization (WHO and definition of the American Society of Hospital Pharmacy (ASHP). ${ }^{12-15}$

All pharmacies and healthcare centers should follow the following policies.

1. If any caregiver in the $\mathrm{MOHs} / \mathrm{PHC}$ centers notices that a patient experiences an ADR, then he/she must assess the patient, including his/her vital signs.

2. The caregiver should record the assessment in the patient's medical record.

3. The caregiver should notify the patient's attending physician for any immediate action that might be needed. The physician may need to change the therapy and/or provide necessary treatment.

4. The caregiver should notify the nursing shift manager. A clear label/ note on the medical record should be affixed in order to indicate that the patient has an allergy from such medication.

5. The caregiver should utilize the ADR Report form (appendix 1) and complete the following information:

$\checkmark$ Patient demographics; $\checkmark$ Suspected drug information;

$\checkmark$ Concomitant drugs;

$\checkmark$ Adverse drug reaction description;

$\checkmark$ Outcome data;

$\checkmark$ Classification of adverse drug reaction according to:

$\checkmark$ The Naranjo causality scale for an adverse drug reaction, (See the Naranjo table and scoring in the attached ADR Form page 3);

$\checkmark$ Adverse drug reaction severity (mild, moderate, or severe);

$\checkmark$ Cost avoidance impact;

$\checkmark$ Name, profession, address, phone and fax.

6. The caregiver, who notifies the ADR, should sign the ADR Report Form and write the date.

7. The caregiver should send the completed ADR Report Form to the Medication Safety Officer in the Pharmacy Department.

8. If the caregiver, while documenting, needs clarification regarding any item that should be completed, then he/she may ask the Medication Safety Officer to assist him in how to fill the required information.

9. The Medication Safety Officer is responsible for sending the com $\neg$ pleted form (And enter the data in the electronic form in the $\mathrm{MOH}$ website) to the GAPC, National Drug Information Center, Medi $\neg$ cation Safety Department.

10. The Medication Safety Officer is responsible for keeping all the original completed ADR Forms confidentially.

11. The Medication Safety Officer is accountable to aggregate the data of all the ADRs reported and formulate a Monthly ADR Summary Report.

12. The Director of Pharmacy or designee shall review all Monthly ADR Summary Report.

13. The Medication Safety Officer is responsible for submitting the Monthly ADR Summary Report to:

$\checkmark$ Quality Department;

$\checkmark$ PTC Committee;

$\checkmark$ Patient Safety Committee;

$\checkmark$ Medication Safety Committee.

14. In addition, the Medication Safety Officer is responsible for submitting the Report of the Independent Case (Considered as sentinel event) to them.

15. An investigation of the ADRs, especially preventable ADRs, causes and contributing factors should be performed and documented by the Medication Safety Officer in coordination with the affected department(s)/ assigned team, or RCA investigation if the case is considered as a sentinel event.

16. All necessary action(s) should be taken with necessary follow-up actions to prevent ADRs, especially preventable ADRs.

\section{Planning Cost Management}

This program needs financial assistance for the education and training of the pharmacy staff, the electronic system for ADR conversion for instant Survey Monkey system and for several other factors related to the pharmacy and the engagement of ADR reporting and documentation purposes.

\section{Execution Phase \\ Management Team}

The management team responsible for the follow-up of the ADR reporting and documentation was the Medications Safety Committee. The 
Central Committee is designed through GAPC at the MOH; The committee consists of representatives from each region specialized in medications safety. A Regional Committee established for each area includes representatives from each hospital and group primary care center. Each hospital or group primary care center creates a Local Medications Safety Committee. The local committee consists of medications safety pharmacists, physicians and nurses and members of quality management and risk management, as well as an invited member. All committees have a monthly meeting to discuss ADR reporting and documentation, ADR analysis and ADR prevention. ${ }^{10}$

\section{Education and Training}

The central committee of medications safety or in the region or peripheral hospital or primary care centers should conduct the several education and training sessions for all stake holders, management team's members and healthcare staff.

\section{Risk Management}

There are six types of risks: budget, scope, personal, schedule, technical and quality risks. Most of the risks experienced might be due to budget or personal and quality risks. A budget risk is related to the unavailability of enough funds for the education and training of the project and for the conversion of the ADR manual documentation to the electronic documentation system. A project might experience personal risks that are related to a shortage of human resources with a high workload of documentation ADR system. In addition, the pharmacy staff might not have received education or training about the project. The project might be exposed to quality risks due to nonqualified pharmacists and due to poor training in the quality pharmacy tools. The project might be exposed to other technical risks such as the nonavailability of an electronic system of ADR documentation with friendly use.

\section{Monitoring and Controlling Phase Project Quality Management}

The following Key Performance Indicators (KPIs) of ADR documentation system was established to monitor the system implementation at $\mathrm{MOH}$ institutions: the adherence documentation of ADR, the cost avoidance analysis of ADR, the ADR analysis with detailed information, the reporting rate of ADR and the number of reporting to SFDA..$^{16,17}$

\section{The Closing of the Project}

The ADR documentation system at $\mathrm{MOH}$ institutions is a critical tool to prevent drug-related problems in the KSA. The system should continue with the corporate committee and other related committees. The annual report of ADR should be done. Education and training courses for healthcare providers should be conducted regularly. Further project expanded to include the cost avoidance of prevention ADR in the future is required and the annual celebration with the project members.

\section{ACKNOWLEDGMENT}

None.

\section{CONFLICT OF INTEREST}

None.

\section{ABBREVIATIONS}

MOH: Ministry of Health; KSA: Kingdom of Saudi Arabia; ADR: Adverse drug reaction; RCA: Root cause analysis; SWOT: Strengths, Weaknesses, Opportunities and Threats; WHO: World Health Organization; SFDA: Saudi Food and Drug Authority; ASHP: American Society of Hospital Pharmacy; PHC: Primary healthcare center; PTC: Pharmacy and Therapeutic Committee; RAPC: Regional Administration of Pharmaceutical Care; GAPC: General Administration of Pharmaceutical Care.

\section{ORCID ID}

Yousef Ahmed Alomi (iD https://orcid.org/0000-003-1381-628X.

\section{REFERENCES}

1. Medication Management (MM). In: National Hospital Standards. $2^{\text {nd }}$ Editio. Saudi Central Board for Accreditation of Healthcare Institutions. 2015;194-211.

2. The Joint Commission. Comprehensive Accreditation Manuals. Joint Commission Resources. 2016

3. American Society of Hospital Pharmacists. ASHP guidelines on preventing medication errors in hospitals. Am J Hosp Pharm. 2018;75:1493-517.

4. Al-Hazmi NN, IL N. A Study of Community Pharmacists? Awareness and Contributions to Adverse Drug Reactions (ADRs) Reporting Systems in the Makkah, Kingdom of Saudi Arabia (KSA). J Clin Trials. 2013;3(1):1-5.

5. Gurmesa LT, Dedefo MG. Factors affecting adverse drug reaction reporting of healthcare professionals and their knowledge, attitude and practice towards ADR reporting in Nekemte Town, West Ethiopia. Biomed Res Int. 2016;2016:58.

6. McDonough R. Writing a Business Plan for a New Pharmacy Service. The Dynamics of Pharmaceutical Care: Enriching Patients' Health. 2010;23.

7. Harris IM, Baker E, Berry TM, Halloran MA, Lindauer K, Ragucci KR, et al. Developing a Business-Practice Model for Pharmacy Services in Ambulatory Settings. Pharmacotherapy. 2008;28(2):7e-34e.

8. Sachdev G. Sustainable business models: Systematic approach toward successful ambulatory care pharmacy practice. Am J Heal Pharm. 2014;71(16):1366-74.

9. PMBOK Guide. A Guide to the Project Management Body of Knowledge. Sixth Edit. Project Management Institute, Inc. 2017.

10. Alomi YA. National Medication Safety Program at Ministry of Health in Saudi Arabia. J Pharmacovigil. 2015;3(5):e145.

11. Government of Saudi Arabia. Saudi Arabia Vision 2030. 2016. [cited 2019 Jan 23] Available from: https://vision2030.gov.sa/sites/default/files/report/Saudi_Vision2030_EN_2017.pdf

12. World Health Organization. Safety of Medicines - A Guide to Detecting and Reporting Adverse Drug Reactions - Why Health Professionals Need to Take Action: Glossary. [cited 2019 Jan 23]. Available from: http://apps.who.int/medicinedocs/en/d/Jh2992e/2.html

13. Saudi Food and Drug Authority. Adverse Drug Reactions (ADRs) Reporting Form for Health Care Professionals. [Cited 2019 Jan 23]. Available from: https://www. sfda.gov.sa/ar/drug/about/sector_departments/national_pharmacovigilance_ center/Documents/ Model for reporting adverse drug reaction and medication errors.pdf

14. Alshammari TM, Alshakka M, Aljadhey H. Pharmacovigilance system in Saudi Arabia. Saudi Pharm J. 2017;25(3):299-305.

15. American Society of Hospital Pharmacists. ASHP guidelines on adverse drug reaction monitoring and reporting. American Society of Hospital Pharmacy. Am J Heal Pharm. 1995;52(4):417-9.

16. Alomi YA, Alghamdi SJ, Alattyh RA. Strategic Plan of General Administration of Pharmaceutical Care at Ministry of Health in Saudi Arabia 2012 - 2022. JPharm Pharm Scien. 2015;1(13):1-8.

17. Alomi Y. National Pharmacy Administration Programs. BAOJ Pharm Sci 2015;1(2):1-2. 
PATIENT DEMOGRAPHICS معلومات المريض

Patient Name (Optional)

رقم الملف:

File Number

Diagnosis:

Past Medical History: اسم المريض ـــ

الوزن: Height $(\mathrm{cm})$ : Weight (kg):

Allergies:

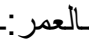
Sex الطول:Height

\section{SUSPECTED DRUG INFORMATIONمعلومات الدواء المسبب للآثار الجانبية}

Drug Name (Brand \& Generic)

Dose / Route / Frequency

Manufacturer \& Batch Number

Manufacture \& Expire Date

Drug, started \& stopped date

Indication of use

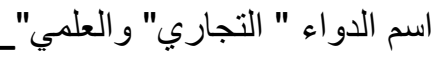

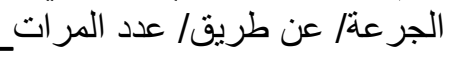

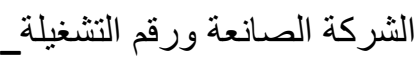
تاريخ الانتاج وتاريخ الانتهاء

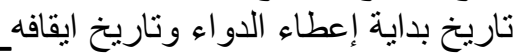

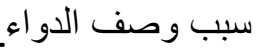

CONCOMITANT DRUGSالأدوية الأخرى

\begin{tabular}{|c|c|c|c|}
\hline $\begin{array}{l}\text { نهاية استخدام الدواء } \\
\text { Date Stopped }\end{array}$ & بداية استخدام الدواء & $\begin{array}{c}\text { عن طريق } \\
\text { Route }\end{array}$ & $\begin{array}{l}\text { الجرعة وعدد المرات } \\
\text { Dose/ Frequency }\end{array}$ \\
\hline & & & \\
\hline & & & \\
\hline & & & \\
\hline & & & \\
\hline & & & \\
\hline
\end{tabular}

Relevant Laboratory Data, Diagnostic Imaging and/ or Biopsy Results(if applicable):

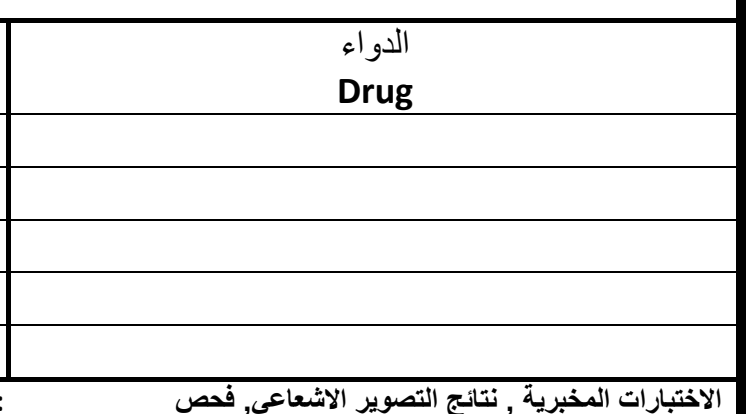

الانسجة (إن وجدات المخئ)

\section{وصف الآثار الجانبية للاواء ADVERSE DRUG REACTION DESCRIPTION}

\section{Adverse Drug Reaction (s) (ADR):}

1.

2.

3.

4.

(ADR) Started \& stopped date:

Did the adverse event(s) appear after the suspected drug was administered? OYESONOO NA Did the reaction(s) stop after stopping drug?

Did the reaction(s) reappear after restarting drug? 


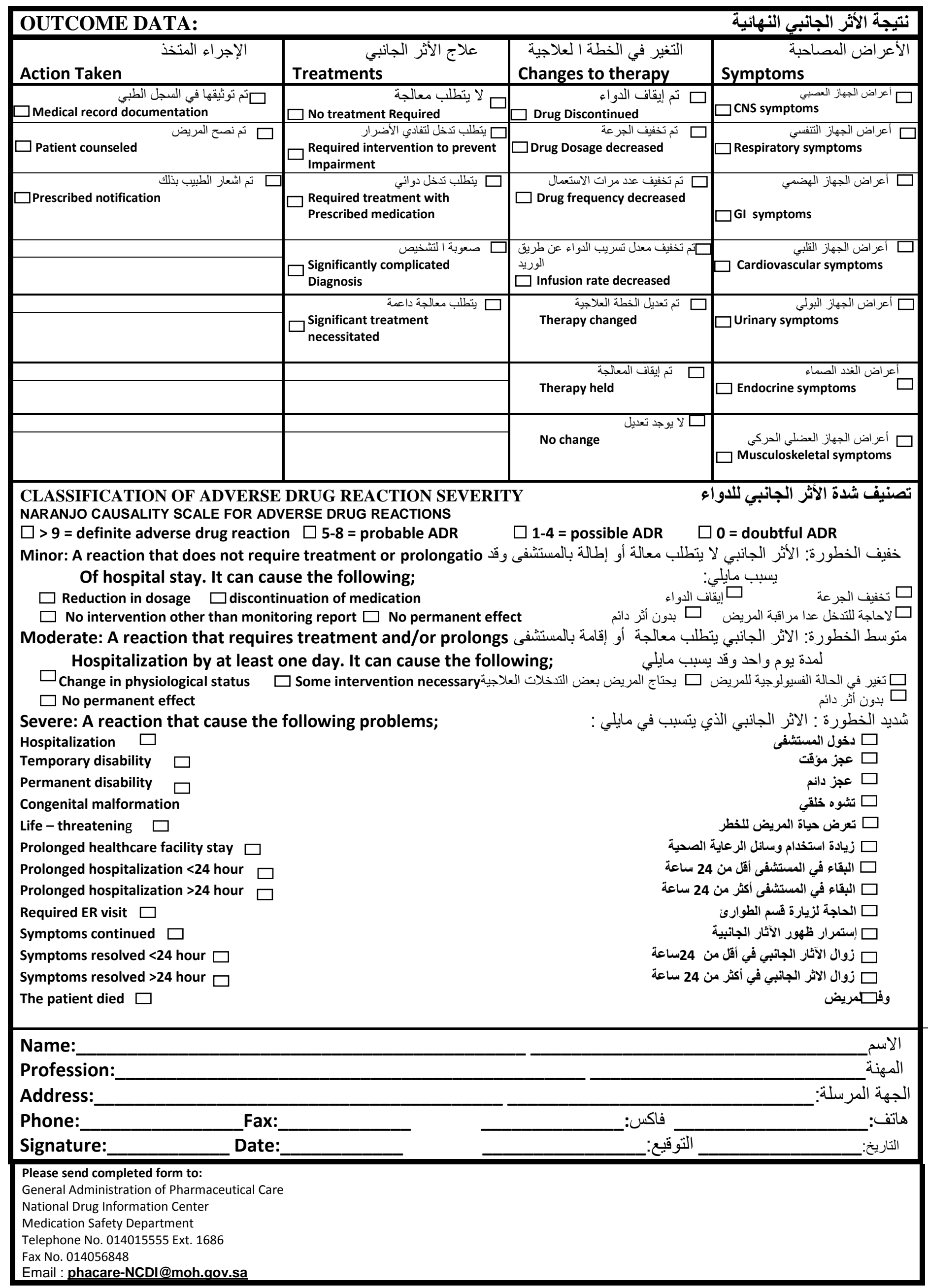

